\title{
The multiple sclerosis rating scale, revised (MSRS-R): Development, refinement, and psychometric validation using an online community
}

\author{
Paul Wicks ${ }^{*}$, Timothy E Vaughan and Michael P Massagli
}

\begin{abstract}
Background: In developing the PatientsLikeMe online platform for patients with Multiple Sclerosis (MS), we required a patient-reported assessment of functional status that was easy to complete and identified disability in domains other than walking. Existing measures of functional status were inadequate, clinician-reported, focused on walking, and burdensome to complete. In response, we developed the Multiple Sclerosis Rating Scale (MSRS).

Methods: We adapted a clinician-rated measure, the Guy's Neurological Disability Scale, to a self-report scale and deployed it to an online community. As part of our validation process we reviewed discussions between patients, conducted patient cognitive debriefing, and made minor improvements to form a revised scale (MSRS-R) before deploying a cross-sectional survey to patients with relapsing-remitting MS (RRMS) on the PatientsLikeMe platform. The survey included MSRS-R and comparator measures: MSIS-29, PDDS, NARCOMS Performance Scales, and MSWS-12.
\end{abstract}

Results: In total, 816 RRMS patients responded (19\% response rate). The MSRS-R exhibited high internal consistency (Cronbach's alpha =.86). The MSRS-R walking item was highly correlated with alternative walking measures (PDDS, $\rho=.84$; MSWS-12, $\rho=.83$; NARCOMS mobility question, $\rho=.86$ ). MSRS-R correlated well with comparison instruments and differentiated between known groups by PDDS disease stage and relapse burden in the past two years. Factor analysis suggested a single factor accounting for $51.5 \%$ of variance.

Conclusions: The MSRS-R is a concise measure of MS-related functional disability, and may have advantages for disease measurement over longer and more burdensome instruments that are restricted to a smaller number of domains or measure quality of life. Studies are underway describing the use of the instrument in contexts outside our online platform such as clinical practice or trials. The MSRS-R is released for use under creative commons license.

Keywords: Multiple sclerosis, Patient-reported outcomes, Disability, MS relapse, Online research, Internet research

\section{Background}

Multiple Sclerosis (MS) is a neurological condition characterised by lesions of myelin sheaths encapsulating the neurons of the brain, spine, and optic nerve, causing transient or progressive symptoms and disability. Measuring MS is challenging; objective measurement requires complex tools (e.g. MRI using an expensive and immobile device), experience (e.g. examination from a specialist neurologist), and/or significant time to complete (e.g. MS Functional Composite, 15 minutes of testing requiring

\footnotetext{
*Correspondence: pwicks@patientslikeme.com

PatientsLikeMe Inc, 155 Second Street, Cambridge, MA 02141, USA
}

special equipment [1]). Patient-perceived symptoms can fluctuate seasonally[2], daily, hourly, or even in response to variations in temperature[3]; they may be unmasked only on specific tasks, and they may involve complex systems such as vision, cognition, sexual function, and bladder function.

The PatientsLikeMe online data platform (www. patientslikeme.com) was built to allow patients with lifechanging illnesses to share data about their experiences of symptoms and disability through structured data collection[4]. Use of the system has shown benefit through improved health literacy, better communication with healthcare professionals, and development of a peer 
support network [5,6]. The platform has proved useful in developing other patient-reported outcomes (PROs) using patients' own language $[7,8]$.

In expanding the platform in 2007 to include MS, a number of instruments were considered. The MS Impact Scale (MSIS-29, [9]) was not intended solely to measure MS disability; it also included health-related functional impact (e.g. limitations in social and leisure activities). The MS Walking Scale (MSWS-12) has the obvious limitation of focusing only on walking $[10,11]$. The North American Research Committee on Multiple Sclerosis (NARCOMS) patient registry has developed validated performance scales (PS) $[12,13]$ in areas including walking, fatigue, cognition, and vision. The PS have clearly defined anchor points for each response; but the instrument is long (about 2,500 words), and the inconsistent response format requires close reading to avoid confusion and erroneous reporting - a potential challenge for patients with cognitive issues and fatigue. NARCOMS has also used the patient-determined disease steps (PDDS) [14], which resembles a patient-reported form of the Expanded Disability Status Scale (EDSS) and may have some of the same limitations as that instrument [15].

In the absence of an agreed-upon "gold standard" PRO, we collaborated with an MS specialist to develop the MS Rating Scale (MSRS). This paper describes the development of the original MSRS, as well as work to revise the scale through cognitive debriefing to produce a revised version (MRSR-R), data on psychometric performance, and comparisons with other patient-reported MS scales.

\section{Methods}

\section{MS Rating Scale (MSRS) Development}

The objective of the MSRS was to accurately quantify the level of MS-relevant disability experienced by patients across a range of domains affected by demyelinating lesions. Observation of an MS specialist's clinic at King's College Hospital in London identified seven domains routinely asked about in clinical practice as part of a "top to toe" clinical interview. These domains were intended to reflect the degree of lesion burden for nervous system regions enervating the region of interest (e.g. optic nerves for "vision"). We adapted a modified scoring scheme from the Guy's Neurological Disability Scale (GNDS[18]), which took a relatively consistent approach to scoring each domain, using the first four levels of disability ("0 - Normal status", "1 - Symptoms causing no disability", "2 - Mild disability not requiring help from others", "3 - Moderate disability requiring help from others") and the final level (4 - "Total loss of function, maximal help required"). A consistent scoring scheme was preferred in order to minimize response burden and encourage repeated entry of data longitudinally. Total score was the sum of the 7 items, with a range of $0-28$. For website display the patient profile rescales the score to a 0-100 scale (Figure 1). Remaining domains from the GNDS, such as "mood" (split into anxiety and depression), bladder, bowel, sexual dysfunction, fatigue and spasms, were integrated into the existing PatientsLikeMe symptoms system and rated by patients as "none"(0), "mild" (1), "moderate" (2), or "severe" (3).

The resulting scale, the MSRS, was felt to have the advantage of tapping a range of important domains for MS patients, not solely focused on walking but including other aspects of function that might be important to monitor over time. Using the MSRS, patients are easily able to create a longitudinal record of their experience of MS to share with others and to help understand the impact of their treatments (Figure 1). At the time of survey invitation (Fall 2010), 15,219 users had completed at least one MSRS survey, for a total of 72,975 reports on the PatientsLikeMe system. Members join the site understanding that their de-identified data will be used for research as part of the terms of service.

\section{Review and Revision of the MSRS Cognitive Interviews}

To test that the instrument captured all domains considered relevant by patients and to identify areas for improvement, patients were recruited for interview by private message on the PatientsLikeMe platform. All patients were local to Boston, Massachusetts and were selected to represent diverse clinical experience. Patients were offered a $\$ 50$ honorarium for their participation, which took approximately 2 hours. Feedback served as the basis for a revised MSRS (MSRS revised, MSRS-R).

The wording of MSRS response options was clarified, defining "disability" more clearly and changing the highest response category from "total" to "severe" disability, along with minor text changes. (see Table 1 for revisions). The domain "upper limb function" was clarified to "using your arms and hands", and "bowel or bladder" dysfunction was added as a domain of functional impairment (see Table 2 for revisions).

\section{Online survey}

The PatientsLikeMe survey system was used to test the psychometric properties of the MSRS-R (incorporating feedback from the cognitive debriefings). The survey consisted of the MSRS-R, a fixed list of MS symptoms, and a report about the patient's most recent relapse. If they chose to report on that relapse, they were asked for start- and end-dates of the relapse, to rate the severity of the relapse ("mild", "moderate", or "severe"), and whether the relapse had required hospitalization or treatment 


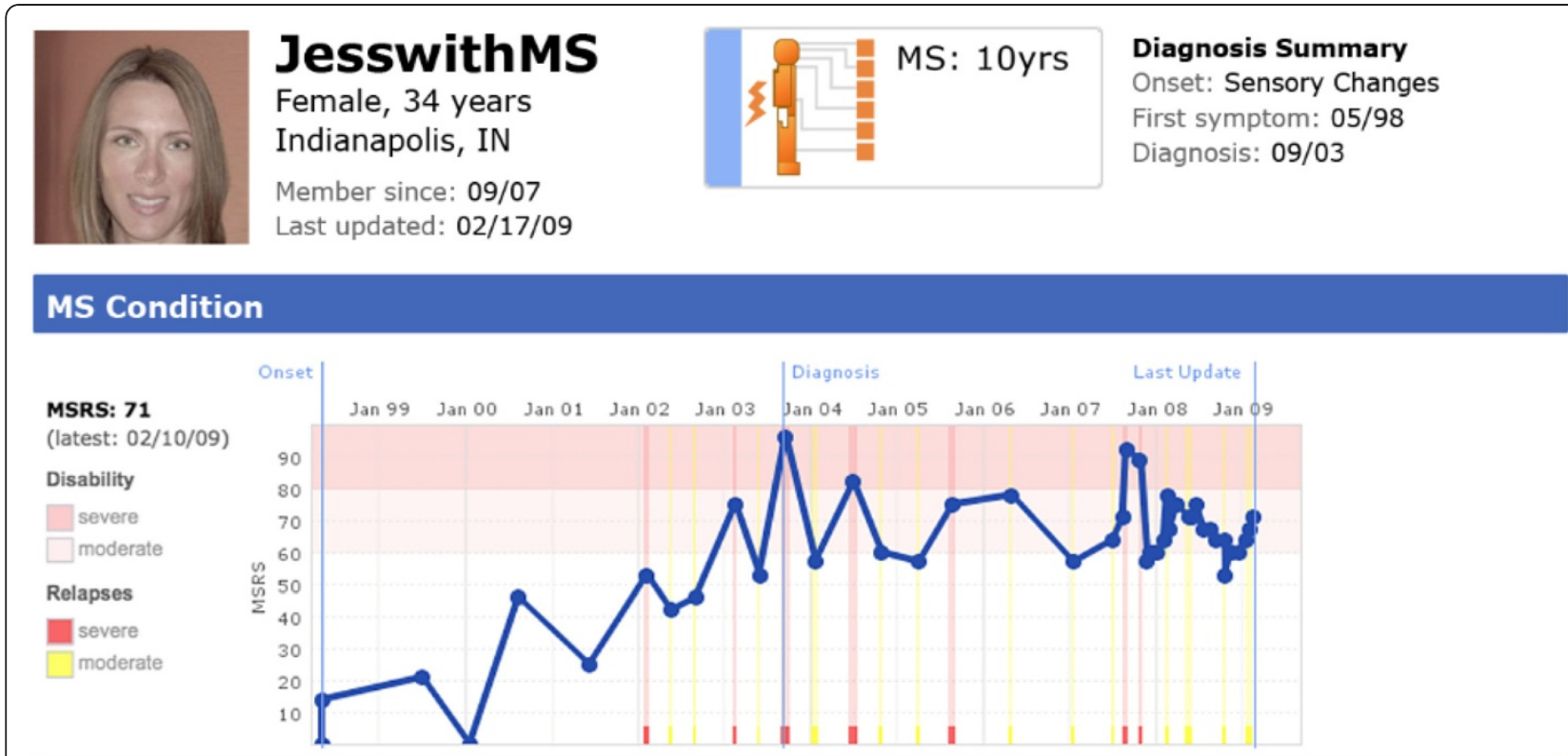

\section{Treatments}
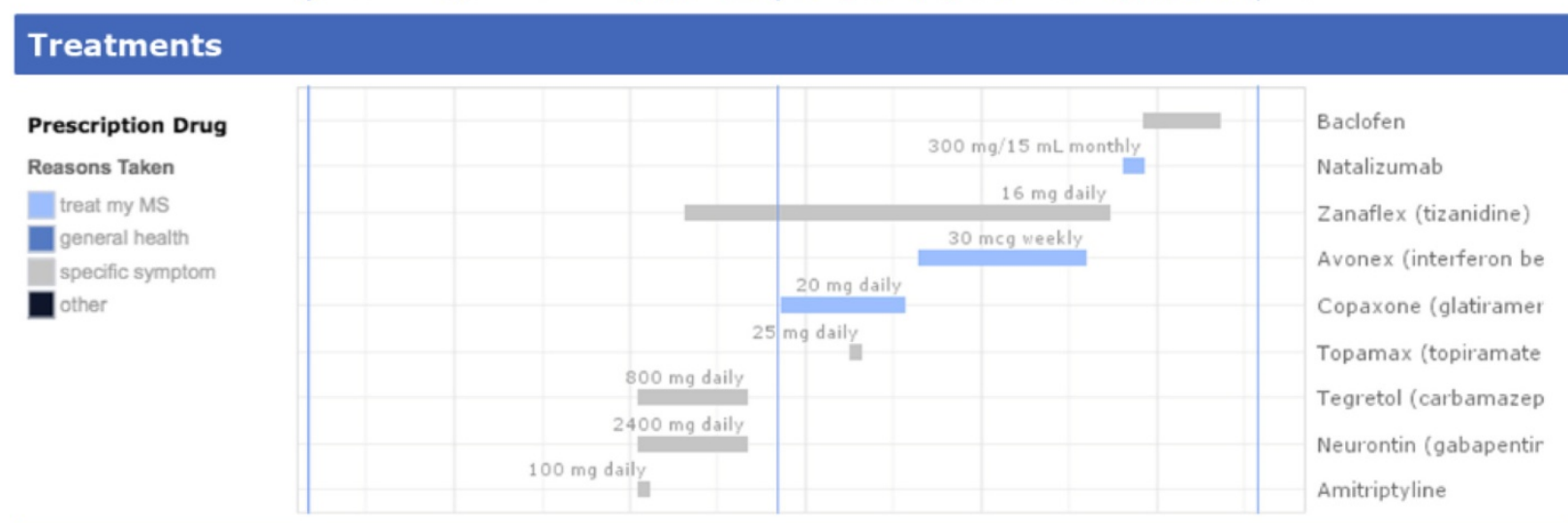

\section{Symptoms}
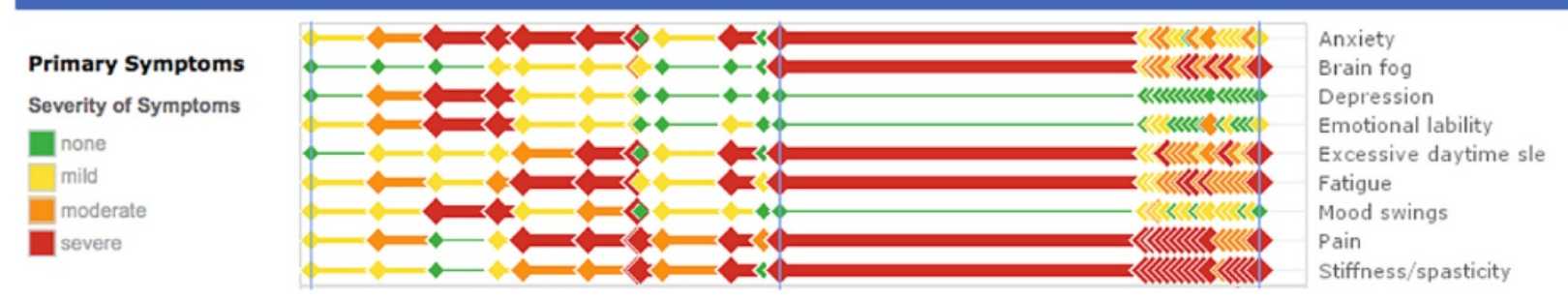

Figure 1 Profile of a sample MS patient featuring rich data and history. Written informed consent was obtained from the patient for publication of this report and any accompanying images.

with steroids, or resulted in any permanent loss of function. The patient then used the MSRS-R to describe their level of disability when they were feeling worst during the relapse.

The remaining sections of the survey were composed of scales identified as being used as secondary outcome measures in clinical trials: the MSIS-29, NARCOMS PS, PDDS, and MSWS-12. Quality-of-life instruments such as the MSQOL-54 were not used because of their predominant focus on QOL as opposed to disability. The
PRIMUS consists of 3 components - 22 symptoms, 15 activities, and 22 quality-of-life statements. We made an error in implementing the quality-of-life component and included only the first 12 items, but fortunately these items sample the full range of item locations on the quality-of-life scale, as described by the PRIMUS developers[16]]. Those who had completed the survey within one week of initial invitation were asked to complete a 1-week retest, which included only the PatientsLikeMe measures. For this follow-up survey the patients were 
Table 1 Original and revised MSRS anchor points

\begin{tabular}{|c|c|}
\hline Original MS Rating Scale (MSRS) & MSRS, Revised (MSRS-R) \\
\hline No Symptoms - No symptoms or disability in this specific area & No Symptoms - No symptoms or disability in this specific area \\
\hline None - Aware of symptoms but no functional disability & $\begin{array}{l}\text { Some Symptoms, No Disability - Aware of symptoms but no } \\
\text { limits on my activities }\end{array}$ \\
\hline Mild - Mild disability but not requiring help from others & $\begin{array}{l}\text { Mild Disability - Mild limits on my activities, but I do not need } \\
\text { help from others or use other aids }\end{array}$ \\
\hline Moderate - Moderate disability that requires some help from others & $\begin{array}{l}\text { Moderate Disability - Moderate limits on my activities, } \\
\text { and I sometimes need help from others or use other aids }\end{array}$ \\
\hline Total Disability - Total disability and help always required & $\begin{array}{l}\text { Severe Disability - Severe limits on my activities, and I usually } \\
\text { need help from others or use other aids }\end{array}$ \\
\hline
\end{tabular}

asked to respond retrospectively about how they were feeling at the time of the first survey. Another instrument, the PRIMUS, was also administered but is not reported here due to the instrument being fielded incorrectly.

Upon site registration, PatientsLikeMe users agree that they may be asked to participate in research; as a research study using only online questionnaires with minimal risk, IRB approval was not sought for this study. However, in accordance with the Declaration of Helsinki, participants were informed about the aims of the study, were given the option to opt-in without incentive and opt-out without any negative consequences. In order to target active users, we invited patients accessing their accounts during the 90 days prior to 24 August 2010. Five days after the initial invitation, a reminder was sent to all invited patients who had not yet completed the survey. At that point an invitation to the retest was also sent to all who had completed the baseline survey within the first six days of the field period. Retest participants also received a reminder 5 days after the retest invitation.

\section{Statistical Analysis}

Data were analyzed using Statistical Package for the Social Sciences (SPSS) V20. Descriptive statistics document

Table 2 Original and revised MSRS items

\begin{tabular}{ll}
\hline $\begin{array}{l}\text { Original MS Rating Scale } \\
\text { (MSRS) }\end{array}$ & MSRS, Revised (MSRS-R) \\
\hline Walking & Walking \\
Upper Limb Function & Using your arms and hands \\
Vision & $\begin{array}{l}\text { Vision (with glasses or contacts if you } \\
\text { use them) }\end{array}$ \\
Speech & Speaking clearly \\
Swallowing & Swallowing \\
Thinking/Memory/Cognition & Thinking, Memory, or Cognition \\
Sensation/Burning/Pain & Numbness, Tingling, Burning Sensation \\
n/a & or Pain \\
\hline
\end{tabular}

the distribution of responses and measurement properties of the MSRS-R. Principal component analysis was used to identify the structure of the MSRS-R. The number of factors was left unconstrained, with eigenvalues $>1$ initially considered worthy of further interest. We also conducted a parallel analysis, using the procedure of Horn [19] and SPSS syntax [20], in order to compare the magnitude of observed eigenvalues against that generated by random arrangements of the same data.

Internal consistency was assessed using item-to-item Spearman correlations and Cronbach's alpha, which should be above 0.7 to be considered adequate. Concurrent validity was tested using correlations between the MSRS-R and other scales, in addition to subscales of the MSIS-29, MSWS-12, and PRIMUS. Test-retest reliability was assessed first with Spearman correlations and then with a Bland-Altman plot.

Known-group validity was assessed by comparing the MSRS-R scores of patients grouped by level of impairment on the self-reported PDDS, which is known to correlate highly with the EDSS, a widely used clinicianrated scale in MS trials. In addition, we used the patient's estimate of the number of relapses they had experienced in the past two years, on the basis that relapses in relapsingremitting MS contribute to a worsening burden of disability [21]. ANOVA (with Bonferroni corrected post-hoc tests) was used to compare MSRS-R scores in the groups, and it was hypothesized that patients in more severe PDDS groups or with a higher number of relapses in the past two years would have worse (higher) MSRS-R scores. Given the prominence of walking measurements in MS, we also performed similar analyses for the MSRS-R walking item. Other between-group differences were assessed using ANOVA, Student's $t$-test, and Kruskal-Wallis tests as appropriate. Clinician-assessed validity and responsiveness to change are the subjects of future investigations.

\section{Results}

\section{Responder characteristics}

Data reported here describe patients who self-reported a diagnosis of relapsing-remitting MS (RRMS), but data 
were also collected for patients with other subtypes (not reported here). The main survey was launched on 8 September 2010. 4,382 invitations were issued to RRMS patients; complete responses were received from 816 RRMS patients (18.6\%); incomplete responses were received from 156 patients (3.6\%, only complete responses are described here), and opt-outs from 121 (2.8\%). The remaining 3,289 (75.1\%) of patients made no response to the survey invitation.

All prospective members of the site are invited to add their age and sex to their profile, but not all had chosen to do so by the time of survey. Using available profile data from non-completers, patients who completed the baseline survey were around 3 years older than noncompleters (see Table 3). The groups differed significantly on sex, although this difference became a non-significant trend after removing patients without ascertained sex $\left(X^{2}(1)=3.476, p=.063\right)$. Baseline completes were also more likely to have reported more relapses on their profile in the 2 years prior to the survey, but this may represent different levels of engagement on the website rather than true disease severity; a similar explanation may underlie for the similar pattern for most recent MSRS score from the patients' profiles.

A little over half of patients reported a recent relapse (52\%, $\mathrm{N}=424 / 816)$. Duration since relapse was distributed between 33\% $(\mathrm{N}=140 / 424)$ reporting one within the month prior to survey completion, 23\% ( $\mathrm{N}=97 / 424)$ reported a relapse between one and three months prior, and $44 \%(\mathrm{~N}=187 / 424)$ reporting a relapse three or more months ago. The vast majority of relapses (98.7\%) were reported from the past decade (2000-2010).

On 14 September, invitations for the 1-week retest were sent to the 391 patients who had completed the survey by this point. 192 RRMS patients (49.1\%) completed the retest survey; $27(6.9 \%)$ provided incomplete answers, and $10(2.6 \%)$ opted out at this stage. The remaining $162(41.4 \%)$ made no response to the retest survey invitation. Participants who completed the retest did not differ on sex, age, disease duration, or disease severity from other eligible participants who took the baseline survey (Table 3), or from those who had not completed the baseline survey in time to be eligible for the retest (not shown). Both surveys were closed to further participation on 23 September 2010.

\section{MSRS-R Psychometric Characteristics}

The revised MSRS-R measure added "bowel or bladder" as a functional area. The revised measure also characterized levels of impairment using more patient-friendly terms around "activity limitation" in contrast to "functional disability", and characterized the most disabled state as "severe" rather than "total disability". Although we did not design the study to compare severity of disability using the original MSRS and the MSRS-R, we did have a small number of respondents $(n=211)$ who had used the original MSRS to populate their site profile within a month of completing the baseline MSRS-R for this study. Table 4 shows somewhat greater use of the extreme disability category ("severe") for the MSRS-R compared with the extreme disability category ("total disability") for the original MSRS.

\section{Factor analysis}

We assessed the dataset for suitability for factor analysis. Given the baseline respondent sample size of 816 , we had approximately 103 participants per variable. Correlations between items were all above $\rho=0.3$. Bartlett's test of sphericity[22] was significant at $\mathrm{p}<0.001$, supporting the factorability of the correlation matrix. The KeyserMeyer-Olkin value of sampling adequacy was 0.884 , exceeding the recommended value of $0.6[23,24]$. PCA revealed a single factor with an eigenvalue of 4.2 accounting for $51.5 \%$ of variance; the second highest eigenvalue was 0.9. Further, the results of a parallel analysis[19] using the same dataset showed no components exceeding the corresponding criterion values ( 8 variables x 816 respondents $x 100$ replications); the highest eigenvalue produced by the parallel analysis was 2.0. Table 5 shows the MSRS-R item factor loadings.

\section{Scale characteristics}

Mean MSRS-R score was 10.9 (SD: 6.1) with a median of 10.0 (IQR: $6-15$ ). Only $0.7 \%$ of patients scored at floor $(\mathrm{MSRS}=0)$, and no patients scored at ceiling $(0 \%$, MSRS $=32$.) Table 6 shows the distribution of item scores; walking $(66.1 \%)$ and sensory aspects $(60.2 \%)$ were the domains most frequently associated with some level of disability; speech (21.5\%) and swallowing (16.6\%) were the least frequently affected.

\section{Internal consistency}

Cronbach's alpha (.86) indicated acceptable internal consistency. Item convergent validity as assessed by correlations between items and total score was also acceptable, ranging from Spearman's rho of $\rho=0.68$ for walking to $\rho=0.77$ for using arms and hands.

\section{Test-retest}

A Bland-Altman plot of the differences in total score at baseline and 1-week retest $(\mathrm{N}=192)$ showed no systematic pattern and no outliers (see Figure 2). The plot showed 182 of 192 cases (95\%) lie within two standard deviations of the mean (mean difference $=0.74$, SD: 2.7, Limits of agreement (+/- 2SD): $-4.6-6.1)$. Examination of item-level differences using a Wilcoxon signed rank test revealed significant differences only for the "Numbness, Tingling, Burning Sensation, or Pain" item 
Table 3 Description of patient samples including completes and non-completes

\begin{tabular}{|c|c|c|c|c|c|c|}
\hline & \multicolumn{3}{|c|}{ Baseline (4,382 eligible) } & \multicolumn{3}{|c|}{ 1-Week Retest (391 eligible) } \\
\hline & Non-Completes & Completes & Sig. & Non-Completes & Completes & Sig. \\
\hline $\mathrm{N}$ of cases & 3566 & 816 & & 199 & 192 & \\
\hline \multicolumn{7}{|l|}{ Sex } \\
\hline Female (\%) & $2715(76.1)$ & $619(75.9)$ & $x^{2}=15.25$ & $151(75.9)$ & $144(75.0)$ & $x^{2}=2.22$ \\
\hline Male (\%) & $622(17.4)$ & $170(20.8)$ & $d f=2$ & $42(21.1)$ & $46(24.0)$ & $d f=2$ \\
\hline Not ascertained (\%) & $229(6.4)$ & $27(3.3)$ & $p<.001$ & $5(2.0)$ & $2(1.0)$ & $p=.329$ \\
\hline \multicolumn{7}{|l|}{ Age in years } \\
\hline Mean (SD) & $42.9(9.9)$ & $45.9(9.8)$ & $t=7.61$ & $45.5(9.9)$ & $46.5(9.5)$ & $\mathrm{t}=.989$ \\
\hline Median (IQR) & $43.0(36-50)$ & $47.0(39-53)$ & $d f=4,102$ & $45.0(38-53)$ & $46.0(40-53)$ & $d f=377$ \\
\hline Range & $15-81$ & $19-73$ & $p<0.001$ & $19-73$ & $21-67$ & $p=.323$ \\
\hline Not ascertained (\%) & $251(7.0)$ & $27(3.3)$ & & $9(4.5)$ & $3(1.6)$ & \\
\hline \multicolumn{7}{|l|}{ Years since MS diagnosis } \\
\hline Mean (SD) & $6.5(6.2)$ & $6.6(6.6)$ & $\mathrm{t}=.79$ & $5.7(7.7)$ & $6.7(6.3)$ & $t=-.106$ \\
\hline Median (IQR) & $4.0(2-9)$ & $4.0(2-9)$ & $d f=4,326$ & $4.0(2-9)$ & $5.0(2-9.8)$ & $\mathrm{df}=388$ \\
\hline Range & $0-39$ & $0-52$ & $p=.430$ & $0-52$ & $0-37$ & $p=.916$ \\
\hline Not ascertained (\%) & $50(1.4)$ & $4(0.5)$ & & $1(0.5 \%)$ & $0(0.0)$ & \\
\hline \multicolumn{7}{|l|}{ Number (\%) of reported relapses in previous 2 years } \\
\hline 0 & $2440(68.4)$ & $471(57.7)$ & $x^{2}=53.82$ & $119(59.8)$ & $108(56.2)$ & $X^{2}=6.14$ \\
\hline 1 & $719(20.2)$ & $182(22.3)$ & $d f=4$ & $45(22.5)$ & $44(22.9)$ & $d f=4$ \\
\hline 2 & $216(6.1)$ & $85(10.4)$ & $p<0.001$ & $20(10.1)$ & $15(7.8)$ & $p=.189$ \\
\hline 3 & $106(3.0)$ & $35(4.3)$ & & $5(2.5)$ & $15(7.8)$ & \\
\hline 4 or more & $85(2.4)$ & $43(5.3)$ & & $10(5.0)$ & $10(5.2)$ & \\
\hline \multicolumn{7}{|l|}{ PDDS group (\%) } \\
\hline normal & $\mathrm{n} / \mathrm{a}$ & $189(23.2)$ & $\mathrm{n} / \mathrm{a}$ & $46(23.1)$ & $42(21.9)$ & $X^{2}=4.55$ \\
\hline mild disability & $\mathrm{n} / \mathrm{a}$ & $107(13.1)$ & & $26(13.1)$ & $26(13.5)$ & $d f=4$ \\
\hline moderate or gait disability & $\mathrm{n} / \mathrm{a}$ & $242(29.7)$ & & $60(30.2)$ & $46(24.0)$ & $p=.225$ \\
\hline early cane & $\mathrm{n} / \mathrm{a}$ & $143(17.5)$ & & $35(17.6)$ & $32(16.7)$ & \\
\hline late cane, bilateral support, wheelchair, or bedridden & $\mathrm{n} / \mathrm{a}$ & $135(16.5)$ & & $32(16.1)$ & $46(24.0)$ & \\
\hline \multicolumn{7}{|l|}{ Most recently entered profile MSRS (\%) } \\
\hline not ascertained & $314(8.8)$ & $25(3.1)$ & $X^{2}=47.515$ & $11(5.5)$ & $1(0.5)$ & $x^{2}=10.24$ \\
\hline 0 to 9 & $341(9.6)$ & $84(10.3)$ & $d f=7$ & $24(12.1)$ & $25(13.0)$ & $d f=7$ \\
\hline 10 to 19 & $511(14.3)$ & $126(15.4)$ & $p<0.001$ & $23(11.6)$ & $31(16.1)$ & $p=.175$ \\
\hline 20 to 29 & $544(15.3)$ & $131(16.1)$ & & $28(14.1)$ & $28(14.6)$ & \\
\hline 30 to 39 & $677(19.0)$ & $132(16.2)$ & & $33(16.6)$ & $33(17.2)$ & \\
\hline 40 to 49 & $413(11.6)$ & $87(10.7)$ & & $20(10.1)$ & $16(8.3)$ & \\
\hline 50 to 59 & $417(11.7)$ & $134(16.4)$ & & $33(16.6)$ & $35(18.2)$ & \\
\hline 60 or higher & $97(11.9)$ & $97(11.9)$ & & $27(13.6)$ & $23(12.0)$ & \\
\hline
\end{tabular}

$(\mathrm{z}=-4.438, \mathrm{p}<0.001)$ with a small effect size $(\rho=.23)$ and mean difference of 1.6 points (SD: 1.1 ).

\section{Concurrent validity}

The MSRS-R total score was correlated significantly $(\mathrm{p}<0.001)$ with all comparable measures using Spearman's rho: MSIS-29 physical subscale $(\rho=.74)$, MSWS-12 $(\rho=.66)$, PDDS $(\rho=.62)$, MSIS-29 psychological subscale $(\rho=60)$. MSRS-R total scores with the NARCOMS PS varied from $\rho=.44$ for depression to $\rho=.63$ for cognitive; but as the NARCOMS PS do not produce a total score, an item-by-item analysis was performed. Table 7 shows the correlations between MSRS-R domains and NARCOMS PDDS and PS item scores; correlations were highest for 
Table 4 Proportion of patients in most extreme disability category in original (MSRS) and revised (MSRS-R) scales

\begin{tabular}{lcc}
\hline MSRS Item & $\begin{array}{c}\text { MSRS: \% of } \\
\text { patients reporting } \\
\text { "total disability" }\end{array}$ & $\begin{array}{c}\text { MSRS-R: \% of } \\
\text { patients reporting } \\
\text { "severe disability" }\end{array}$ \\
\hline Walking & 8 & 18 \\
Upper limb / & 1 & 1 \\
Arms and Hands & 1 & 3 \\
Vision & 0 & 1 \\
Speaking & 0 & 1 \\
Swallowing & 2 & 4 \\
Thinking, memory, & & 13 \\
or cognition & 8 & \\
Numbness, tingling, \\
burning sensation, pain
\end{tabular}

walking $(\rho=.84)$, with the remainder of correlations between MSRS-R domains and their relevant PS item scores around $\rho=.7$, indicating good agreement.

\section{Known group validity}

We hypothesized that higher total MSRS-R scores (worse disability) would be observed for those with worsening PDDS status and a higher number of relapses.

Between-groups differences on MSRS-R by PDDS levels were found to be significant using ANOVA $(F(7,808)=77.250, p<.001)$. Post-hoc Bonferroni tests of all pair-wise comparisons revealed significant differences between MSRS-R for normal and mild PDDS from all other PDDS levels $(\mathrm{p}<.001)$. "Moderate" and "Gait disability" PDDS levels were not significantly different from one another $(p>0.05)$. Higher levels of mobility impairment ("early cane", "late cane", "bilateral support") differed significantly from "normal", "mild", and "moderate" disability, but not from each other $(\mathrm{p}>0.05)$. "Use of a wheelchair or scooter" differed only from "normal" or "mild" disability $(\mathrm{p}<0.05)$ on the MSRS-R. No respondents endorsed the most severe category on the PDDS ("Bedridden"). Examination of individual MSRS-R items revealed a much stronger step-wise relationship between

Table 5 Principal component analysis item loadings for a single factor (eigenvalue $4.2,51.5 \%$ of variance)

\begin{tabular}{lc}
\hline MSRS-R Item & $\begin{array}{l}\text { Factor } \\
\text { Loading }\end{array}$ \\
\hline Walking & .639 \\
Using your arms and hands & .770 \\
Vision (with glasses or contacts if you use them) & .708 \\
Speaking clearly & .751 \\
Swallowing & .737 \\
Bowel or bladder & .662 \\
Thinking, memory, or cognition & .739 \\
Numbness, tingling, burning sensation, or pain & .723 \\
\hline
\end{tabular}

PDDS and the MSRS-R walking item than other items, although "bladder \& bowel" shows a similar, though less marked pattern (Table 8).

Our second known group comparison consisted of comparing MSRS-R scores against the number of selfreported MS relapses on patients' profiles for the two years preceding the survey (Table 9). One-way ANOVA showed significant differences for total MSRS-R score $(\mathrm{F}(4,811)=6.422, \mathrm{p}<0.001)$. Two post-hoc Bonferroni tests were significant: between "no relapses reported" and " 4 or more" (mean difference: 4.3, 95\% CI: 1.6-6.9, $\mathrm{p}<0.001)$ and between "1 relapse" and " 4 or more" (mean difference: 3.3, 95\% CI: 0.5-6.1, p $<0.001$ ). We also checked whether PDDS were significantly different across recent burden of relapses using a Kruskal-Wallis test and found no significant difference $\left(X^{2}(4)=5.093\right.$, $\mathrm{p}=.278)$.

\section{MSRS-R in retrospectively reported relapses}

Within MSRS-R scores for retrospectively reported relapses captured actively in the survey (as opposed to passively in the patient's site profile), Figure 3 shows the difference between MSRS-R at baseline and most recent relapse according to the perceived severity of the relapse ("mild", "moderate", or "severe", $\mathrm{N}=424$ ). The largest differences were reported, on average, for walking, upper limb function, and the sensations (numbness, tingling, burning, and pain), followed by vision, speaking, and then swallowing.

\section{Discussion}

The original MSRS was designed to minimize respondent burden, using a minimum number of items to cover relevant aspects of patient experience and simple, clear language in both the questions and response options. Patients have indicated in qualitative interviews that the questions are relevant to their experience, easy to understand, and easy to respond to, and provide an accurate profile of their experience of MS over time. Its deployment on PatientsLikeMe led to widespread use by thousands of MS patients, who report that using the site has produced a number of benefits including improved understanding of their condition and improved communication with their healthcare providers[5]. Following cognitive debriefing, a number of small modifications were made to produce the MSRS-R (Revised). After fielding in a survey, statistical analysis shows the MSRS$\mathrm{R}$ exhibits desirable psychometric properties in terms of ceiling and floor effects, internal consistency, factor structure, test-retest, and known-group validity. Importantly, the MSRS-R correlated in expected ways with alternative measures in widespread use (MSIS-29, PDDS, NARCOMS PS, and MSWS-12), suggesting acceptable concurrent validity and potential use as a research tool. 
Table 6 MSRS-R item distributions

\begin{tabular}{|c|c|c|c|c|c|}
\hline \multirow[t]{2}{*}{ Current MSRS-R ( $\mathrm{N}=816)$} & No Symptoms & Some symptoms, No Disability & Mild Disability & Moderate Disability & Severe Disability \\
\hline & $\begin{array}{l}\text { No symptoms or disability } \\
\text { in this specific area }\end{array}$ & $\begin{array}{l}\text { Aware of symptoms but no } \\
\text { limits on my activities }\end{array}$ & $\begin{array}{l}\text { Mild limits on my activities, } \\
\text { but I do not need help from } \\
\text { others or use other aids }\end{array}$ & $\begin{array}{l}\text { Moderate limits on my activities } \\
\text { and I sometimes need help from } \\
\text { others or use other aids }\end{array}$ & $\begin{array}{l}\text { Severe limits on my activities } \\
\text { and I usually need help from } \\
\text { others or use other aids }\end{array}$ \\
\hline Walking & $12.4 \%$ & $21.6 \%$ & $24.4 \%$ & $33.7 \%$ & $8.0 \%$ \\
\hline Using your arms and hands & $26.8 \%$ & $33.5 \%$ & $25.4 \%$ & $13.5 \%$ & $0.9 \%$ \\
\hline $\begin{array}{l}\text { Vision (with glasses or } \\
\text { contacts if you use them) }\end{array}$ & $35.0 \%$ & $31.0 \%$ & $19.2 \%$ & $12.7 \%$ & $2.0 \%$ \\
\hline Speaking Clearly & $47.2 \%$ & $31.3 \%$ & $15.8 \%$ & $5.6 \%$ & $0.1 \%$ \\
\hline Swallowing & $55.6 \%$ & $27.7 \%$ & $12.6 \%$ & $3.9 \%$ & $0.1 \%$ \\
\hline Bowel or bladder & $25.5 \%$ & $27.7 \%$ & $26.3 \%$ & $16.4 \%$ & $4.0 \%$ \\
\hline Thinking, Memory, or Cognition & $16.7 \%$ & $32.5 \%$ & $26.7 \%$ & $19.9 \%$ & $4.3 \%$ \\
\hline $\begin{array}{l}\text { Numbness, Tingling, } \\
\text { Burning Sensation or Pain }\end{array}$ & $11.0 \%$ & $28.7 \%$ & $27.2 \%$ & $24.1 \%$ & $8.9 \%$ \\
\hline
\end{tabular}




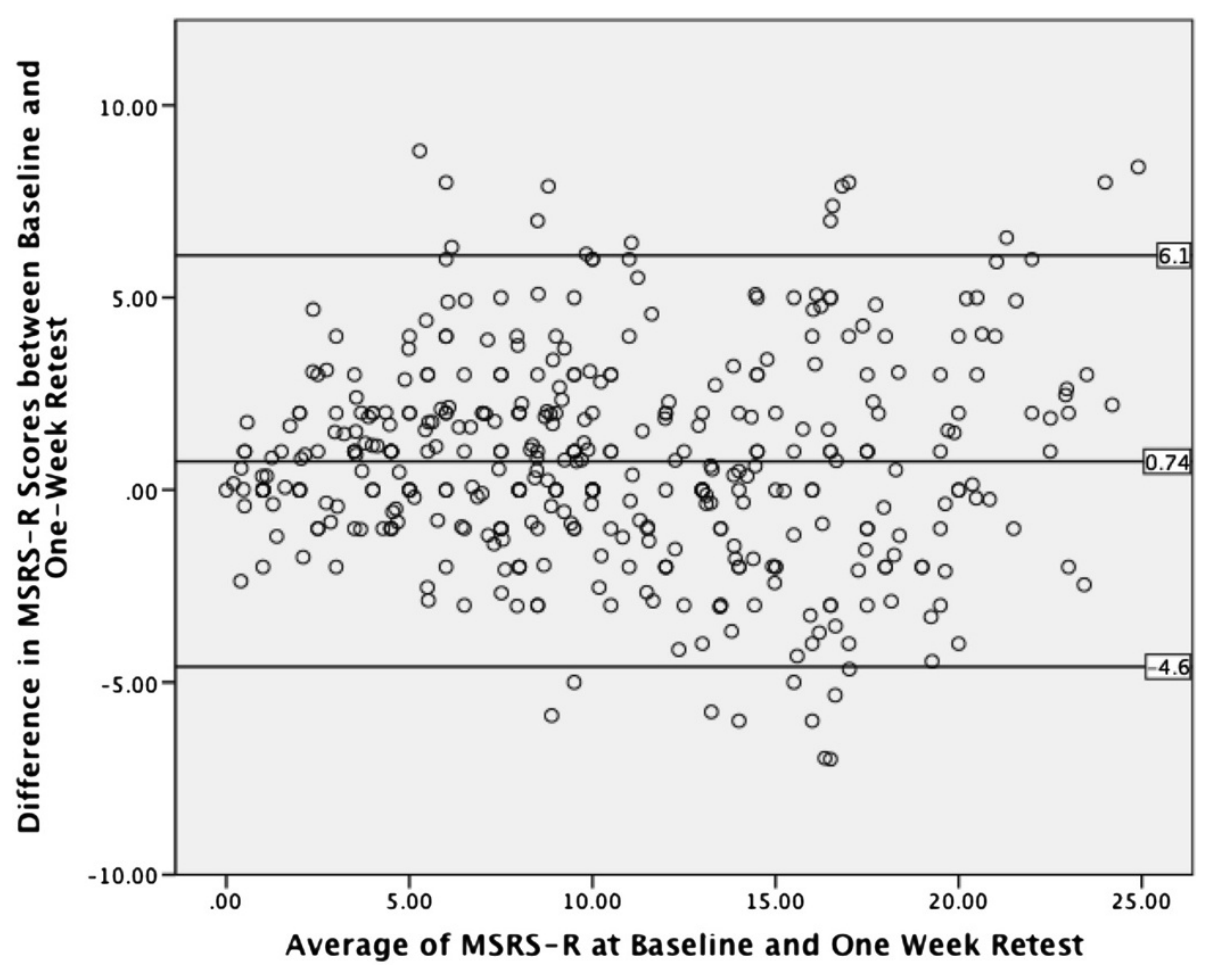

Figure 2 Bland-Altman plot for baseline and 1-week retest MSRS-R.

The MSRS-R has the advantage of being more concise than any of the other instruments fielded in this study; for instance, the PDDS requires a patient to read approximately 360 written words to gauge walking disability; the MSRS-R walking item has 33 words and produces very similar results. Furthermore, our analysis confirmed that the PDDS, like the EDSS it is based upon, is predominantly focused on walking; by contrast, the entire MSRS-R covers eight domains but is only 53 words long and uses a consistent response format, which makes it less burdensome for patients to read and complete.
Currently, MS trial design focuses on the frequency of relapses but is uninformed by the nature of these relapses, and so an attack that leaves one patient unable to walk and another unable to see are counted the same. Analysis of retrospective relapses in the current study demonstrated that the nature of relapses experienced in this population could be characterized by changes from baseline within specific domains of function using the MSRS-R. This may be useful in improving our understanding of MS characterization, progression, and response to therapy. In addition, our known group validity analysis

Table 7 Correlations (Spearman's rho) between MSRS-R domains and PDDS and NARCOMS Performance Scales $(p<0.001)$

\begin{tabular}{|c|c|c|c|c|c|c|c|c|c|c|c|c|}
\hline \multirow[b]{2}{*}{ MSRS-R Domains } & \multicolumn{12}{|c|}{ NARCOMS } \\
\hline & PDDS & Mobility & Hand & Vision & Fatigue & Cognitive & $\begin{array}{l}\text { Bladder/ } \\
\text { Bowel }\end{array}$ & Sensory & Spasticity & Pain & Depression & Tremor \\
\hline Walking & 0.84 & 0.84 & 0.43 & 0.25 & 0.44 & 0.27 & 0.44 & 0.41 & 0.55 & 0.40 & 0.25 & 0.53 \\
\hline Using your arms and hands & 0.48 & 0.47 & 0.70 & 0.38 & 0.48 & 0.44 & 0.28 & 0.56 & 0.50 & 0.50 & 0.32 & 0.49 \\
\hline $\begin{array}{l}\text { Vision (with glasses or contacts } \\
\text { if you use them) }\end{array}$ & 0.28 & 0.28 & 0.35 & 0.71 & 0.35 & 0.42 & 0.26 & 0.36 & 0.32 & 0.40 & 0.32 & 0.32 \\
\hline Speaking Clearly & 0.28 & 0.27 & 0.42 & 0.38 & 0.37 & 0.47 & 0.23 & 0.32 & 0.28 & 0.36 & 0.27 & 0.35 \\
\hline Swallowing & 0.32 & 0.32 & 0.39 & 0.36 & 0.39 & 0.43 & 0.30 & 0.38 & 0.33 & 0.39 & 0.30 & 0.35 \\
\hline Bowel or bladder & 0.48 & 0.46 & 0.30 & 0.30 & 0.37 & 0.34 & 0.71 & 0.35 & 0.36 & 0.32 & 0.25 & 0.36 \\
\hline Thinking, Memory, or Cognition & 0.28 & 0.26 & 0.37 & 0.41 & 0.49 & 0.77 & 0.28 & 0.38 & 0.34 & 0.44 & 0.42 & 0.42 \\
\hline $\begin{array}{l}\text { Numbness, Tingling, Burning } \\
\text { Sensation or Pain }\end{array}$ & 0.45 & 0.42 & 0.48 & 0.36 & 0.51 & 0.45 & 0.31 & 0.72 & 0.53 & 0.67 & 0.38 & 0.47 \\
\hline
\end{tabular}


Table 8 Comparison of MSRS-R and MSRS-R items by known PDDS groups

\begin{tabular}{|c|c|c|c|c|c|c|c|c|c|c|}
\hline Mean (S.D) & $\begin{array}{c}\mathrm{n} \text { of } \\
\text { cases }\end{array}$ & $\begin{array}{l}\text { Total } \\
\text { MSRS-R } \\
(0-32)\end{array}$ & $\begin{array}{c}\text { Walking } \\
(0-4)\end{array}$ & $\begin{array}{c}\text { Arms \& } \\
\text { Hands } \\
(0-4)\end{array}$ & $\begin{array}{l}\text { Vision } \\
(0-4)\end{array}$ & $\begin{array}{l}\text { Speaking } \\
(0-4)\end{array}$ & $\begin{array}{c}\text { Swallowing } \\
(0-4)\end{array}$ & $\begin{array}{c}\text { Bowel \& } \\
\text { Bladder } \\
(0-4)\end{array}$ & $\begin{array}{l}\text { Thinking, } \\
\text { Memory, } \\
\text { Cognition } \\
(0-4)\end{array}$ & $\begin{array}{c}\text { Numbness, } \\
\text { Tingling, Burning } \\
\text { Sensation } \\
\text { or Pain }(0-4)\end{array}$ \\
\hline \multicolumn{11}{|l|}{ PDDS group } \\
\hline \multirow[t]{2}{*}{0 - normal } & 189 & 4.9 & 0.7 & 0.5 & 0.6 & 0.3 & 0.2 & 0.7 & 1.0 & 1.1 \\
\hline & & (3.5) & $(0.7)$ & $(0.7)$ & $(0.8)$ & $(0.5)$ & $(0.5)$ & $(0.8)$ & $(0.8)$ & $(0.8)$ \\
\hline \multirow[t]{2}{*}{1 - mild disability } & 107 & 8.8 & 1.4 & 0.9 & 0.9 & 0.7 & 0.5 & 1.2 & 1.5 & 1.6 \\
\hline & & $(4.5)$ & $(7.5)$ & $(0.8)$ & $(0.9)$ & $(0.8)$ & $(0.8)$ & $(1.0)$ & $(1.0)$ & $(1.0)$ \\
\hline \multirow[t]{2}{*}{2 - moderate } & 99 & 11.8 & 1.8 & 1.4 & 1.5 & 1.0 & 0.6 & 1.4 & 2.0 & 2.0 \\
\hline & & $(4.2)$ & $(0.8)$ & $(0.8)$ & $(1.1)$ & $(0.9)$ & $(0.8)$ & $(1.0)$ & $(1.0)$ & $(1.0)$ \\
\hline \multirow[t]{2}{*}{3 - gait disability } & 143 & 12.3 & 2.4 & 1.6 & 1.3 & 0.9 & 0.8 & 1.5 & 1.8 & 2.1 \\
\hline & & $(4.8)$ & $(0.6)$ & $(1.0)$ & $(1.0)$ & $(0.9)$ & $(0.8)$ & $(1.0)$ & $(1.1)$ & $(1.0)$ \\
\hline \multirow[t]{2}{*}{4 - early cane } & 143 & 14.1 & 2.9 & 1.6 & 1.4 & 1.0 & 0.9 & 2.0 & 1.9 & 2.4 \\
\hline & & $(5.7)$ & $(0.5)$ & $(1.0)$ & $(1.1)$ & $(1.0)$ & $(0.9)$ & $(1.1)$ & $(1.1)$ & $(1.1)$ \\
\hline \multirow[t]{2}{*}{5 - late cane } & 90 & 15.9 & 3.3 & 2.0 & 1.7 & 1.2 & 1.1 & 2.0 & 2.0 & 2.6 \\
\hline & & (5.3) & $(0.5)$ & $(0.9)$ & (1.3) & $(1.0)$ & $(1.0)$ & $(1.0)$ & $(1.2)$ & $(1.1)$ \\
\hline \multirow[t]{2}{*}{6 - bilateral support } & 31 & 15.5 & 3.5 & 1.9 & 1.4 & 1.0 & 0.9 & 2.7 & 1.8 & 2.4 \\
\hline & & $(5.4)$ & $(0.5)$ & $(1.1)$ & $(1.1)$ & $(1.0)$ & $(1.1)$ & $(1.0)$ & $(1.0)$ & $(1.2)$ \\
\hline \multirow[t]{2}{*}{ 7- wheelchair or scooter } & 14 & 13.4 & 3.9 & 1.4 & 1.0 & 0.9 & 0.9 & 2.3 & 1.2 & 2.1 \\
\hline & & $(5.5)$ & $(0.4)$ & (1.3) & $(0.3)$ & $(1.1)$ & $(1.0)$ & $(1.2)$ & $(1.2)$ & $(1.7)$ \\
\hline 8 - bedridden & 0 & $\mathrm{n} / \mathrm{a}$ & $\mathrm{n} / \mathrm{a}$ & $\mathrm{n} / \mathrm{a}$ & $\mathrm{n} / \mathrm{a}$ & $\mathrm{n} / \mathrm{a}$ & $\mathrm{n} / \mathrm{a}$ & $\mathrm{n} / \mathrm{a}$ & $\mathrm{n} / \mathrm{a}$ & $\mathrm{n} / \mathrm{a}$ \\
\hline
\end{tabular}

suggested that the MSRS-R might be more sensitive to cumulative burden of disability resulting from recurrent relapses than the PDDS; further study could compare MSRS-R against other measures of cumulative burden such as magnetic resonance imaging.

Following this psychometric validation and upgrade of the existing MSRS to the newer MSRS-R, passively collected profile data in the PatientsLikeMe platform could be studied as a form of observational registry combining demographic, social networking, treatment, and symptom data. Such data would extend to a larger number of patients than described here, and to MS disease types other than RRMS, and could illuminate the real-world impact of newer therapies for MS. For instance, it may be particularly interesting to retrieve the prospective data for patients who did not report any treatment at the time

Table 9 Comparison of MSRS-R by number of MS relapses reported on profile in the past two years

\begin{tabular}{lcc}
\hline $\begin{array}{l}\text { Number of relapses in } \\
\text { previous 2 years }\end{array}$ & $\mathbf{N}$ & $\begin{array}{c}\text { Total MSRS-R } \\
\mathbf{( 0 - 3 2 )}\end{array}$ \\
\hline 0 (none reported) & 471 & $10.2(5.8)$ \\
1 & 182 & $11.2(5.9)$ \\
2 & 85 & $11.9(6.3)$ \\
3 & 35 & $12.0(6.7)$ \\
4 or more & 43 & $14.5(7.1)$ \\
\hline
\end{tabular}

of creating their account and study the amount of MSRS-R change that triggers initiation of treatment, or to gauge the effectiveness of treatment in stabilizing or reducing disability relative to similar patients who did not start treatment.

With regard to administration, although we did not explicitly test for differences between, e.g., paper-andpencil questionnaires compared with online questionnaires, we expect that there would be no or minimal difference between data collected in these modes. The cognitive interviews did not suggest any significant difference between patients' responses on paper and how they would have responded (or how they had responded previously) using the report tools on the PatientsLikeMe platform. The online form is two-dimensional, and no wording or format changes are required to adapt the MSRS-R, symptoms, or relapse questions for paper-andpencil administration.

The limitations of this study are shared by many postal or internet-based questionnaire designs. We have no independent validation that respondents actually do have MS; however, as there was no incentive for participating, there would be little incentive to enter false data. Our analysis of responders found them to be a little older and more affected by MS than non-respondents; this is perhaps unsurprising given that sicker patients may be more inclined to return to PatientsLikeMe to seek support. One 


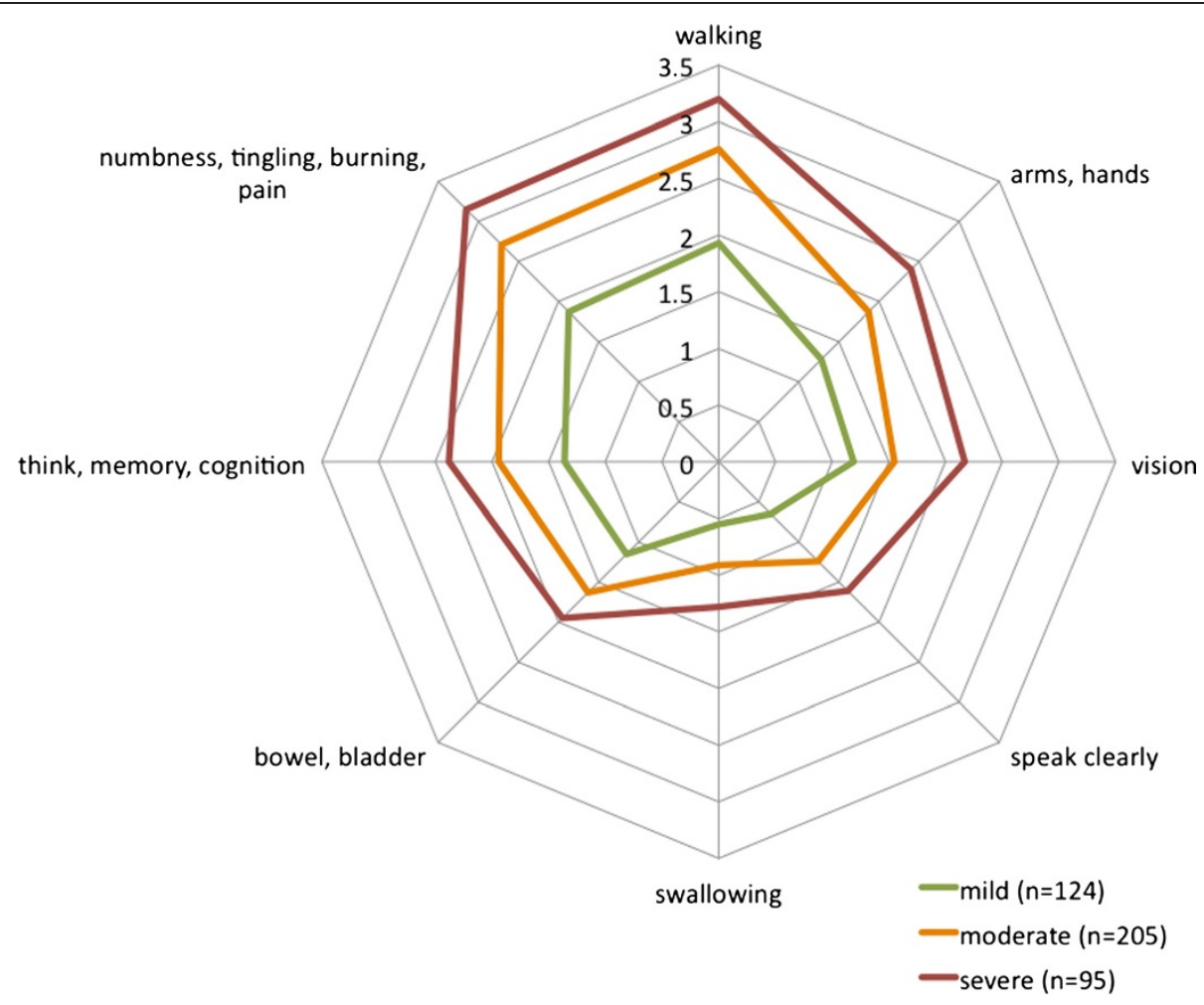

Figure 3 Spider plot of MSRS-R domain differences between baseline MSRS-R score and 'most recent' relapse, broken out by severity.

advantage of this data collection platform is that we can systematically describe the population of non-responders.

It is likely that the entire PatientsLikeMe population may differ systematically from the broader MS population (see [8] for a comparison with the Sonya Slifka Longitudinal MS Study), therefore these findings should be generalized cautiously. That said, our findings on the response characteristics of the comparison instruments used proved similar to their own validation studies. The response rate (19\%) was relatively low but was not atypical for a survey of this online community[5]. The most significant limitation was that we lacked independent clinical assessment of disease severity from a clinician experienced in the field; we are seeking to address this in future studies.

A further limitation that underscores the difference between passively collected profile data and actively sampled survey data is the mismatch between the 345 completers (43\%) who had at least one relapse recorded on their profile and the 424 completers (52\%) who reported having at least one relapse when polled on the survey. Passively collected data provides a large body of longitudinal data but suffers from attrition bias; actively collected data provides a more accurate cross-section at one or a few points in time but is more costly to collect and may suffer from responder bias.

Evaluating the quality of the test-retest with a BlandAltman plot is difficult in the absence of a gold standard and the lack of agreed standards for measurement variability in MS. It is possible that in performing the testretest, some patients may not have clearly read the instructions to report retrospectively to the first time they completed the survey; if so, the degree of test-retest agreement reported here would be an underestimate and should be investigated further.

A copy of the MSRS-R is included as an appendix to this manuscript, and the instrument is distributed with a Creative Commons "Attribution-ShareAlike3.0 Unported" license, meaning it can be used freely (including commercially), altered, transformed, or built upon, so long as all derivative work is licensed in the same fashion and proper attribution is made (Additional file 1).

\section{Conclusion}

The MSRS-R has been shown to be a useful tool for measuring the impact of MS and may help patients and clinicians understand the course of disease, the impact of their treatments, side effects, and relapses. It is hoped that an enhanced understanding of these aspects of MS may help improve patients' outcomes.

\section{Additional file}

Additional file 1: Multiple Sclerosis Rating Scale (Revised): MSRS-R [25]. 


\section{Abbreviations}

EDSS: Expanded Disability Status Scale; GNDS: Guy's Neurological Disability Scale; MRI: Magnetic Resonance Imaging; MS: Multiple Sclerosis; MSIS-29: 29-item Multiple Sclerosis Impact Scale; MSRS: MS Rating Scale; MSRS-R: MS Rating Scale (Revised); MSWS-12: 12-item Multiple Sclerosis Walking Scale; NARCOMS: North American Research Committee on MS Registry: PCA: Principal Component Analysis; PDDS: Patient-Determined Disease Steps; PLM-QOL: PatientsLikeMe Quality of Life scale; PPMS: Primary Progressive Multiple Sclerosis; PRO: Patient Reported Outcome; PS: Performance Scales; QOL: Quality of Life; RRMS: Relapsing-Remitting Multiple Sclerosis; SPMS: Secondary Progressive Multiple Sclerosis; SPSS: Statistical Package for the Social Sciences.

\section{Competing interests}

PW, TV, \& MM are all current or former employees of PatientsLikeMe and hold stock / stock options in the company. The PatientsLikeMe R\&D team has received research support from Abbott, Accorda, Avanir, Biogen, Genzyme, Merck, Novartis, Sanofi and UCB.

\section{Authors' contributions}

PW: Designed MSRS, project design, revised manuscript, statistical analysis. TV: Data analysis, reviewed manuscript. MM: Drafted manuscript, project design, cognitive debriefing, statistical analysis. All authors read and approved the final manuscript.

\section{Acknowledgements}

The authors are grateful to Eli Silber who provided input to the original version of the MSRS, Kate Slawsky for providing input on the draft manuscript, Shivani Bhargava for assistance in managing the recruitment and completion of cognitive interviews, David Hoaglin and Brian Healy for statistical advice, and to the many patient members of PatientsLikeMe's MS community who contributed their data, time, and feedback to this project.

Received: 22 September 2011 Accepted: 4 June 2012

Published: 18 June 2012

\section{References}

1. Fischer JS, Rudick RA, Cutter GR, Reingold SC: The Multiple Sclerosis Functional Composite measure (MSFC): an integrated approach to MS clinical outcome assessment. Mult Scler 1999, 5(4):244.

2. Meier DS, Balashov KE, Healy B, Weiner HL, Guttmann CRG: Seasonal prevalence of MS disease activity. Neurology 2010, 75(9):799.

3. Leavitt VM, Sumowski JF, Chiaravolloti ND, De Luca J: Warmer Daily Temperature is Associated with Worse Cognitive Functioning in Multiple Sclerosis [abstract]. Neurology 2011, 76:A81.

4. Brownstein CA, Brownstein JS, Williams DS III, Wicks P, Heywood JA: The power of social networking in medicine. Nat Biotechnol 2009, 27(10):888-890.

5. Wicks P, Massagli M, Frost J, Brownstein C, Okun S, Vaughan T, Bradley R, Heywood J: Sharing Health Data for Better Outcomes on PatientsLikeMe. J Med Internet Res 2010, 12(2):e19.

6. Wicks $P$, Keininger DL, Massagli MP, de la Loge C, Brownstein C, Isojarvi J, Heywood J: Perceived benefits of sharing health data between people with epilepsy on an online platform. Epilepsy Behav 2012, 23(1):16-23.

7. Wicks P, Massagli MP, Wolf C, Heywood J: Measuring function in advanced ALS: validation of ALSFRS-EX extension items. Eur J Neurol 2009, 16(3):353-359,

8. Wicks P, Massagli MP, Kulkarni A, Dastani H: Use of an Online Community to Develop Patient-Reported Outcome Instruments: The Multiple Sclerosis Treatment Adherence Questionnaire (MS-TAQ). J Med Internet Res 2011, 13(1):e12.

9. Hobart J, Lamping D, Fitzpatrick R, Riazi A, Thompson A: The Multiple Sclerosis Impact Scale (MSIS-29): a new patient-based outcome measure. Brain 2001, 124(5):962.

10. Goodman AD, Brown TR, Krupp LB, Schapiro RT, Schwid SR, Cohen R, Marinucci LN, Blight AR: Sustained-release oral fampridine in multiple sclerosis: a randomised, double-blind, controlled trial. Lancet 2009, 373(9665):732-738

11. Hobart JC, Riazi A, Lamping DL, Fitzpatrick R, Thompson AJ: Measuring the impact of MS on walking ability: the 12-ltem MS Walking Scale (MSWS-12). Neurology 2003, 60(1):31.
12. Marrie RA, Cutter G, Tyry T, Hadjimichael $\mathrm{O}$, Campagnolo D, Vollmer T: Validation of the NARCOMS registry: fatigue assessment. Mult Scler 2005 11(5):583-584.

13. Marrie RA, Cutter $\mathrm{G}$, Tyry $\mathrm{T}$, Hadjimichael $\mathrm{O}$, Vollmer T: Validation of the NARCOMS Registry: pain assessment. Mult Scler 2005, 11(3):338-342.

14. Hohol MJ, Orav EJ, Weiner HL: Disease steps in multiple sclerosis: a simple approach to evaluate disease progression. Neurology 1995, 45(2):251-255.

15. Hobart J, Freeman J, Thompson A: Kurtzke scales revisited: the application of psychometric methods to clinical intuition. Brain 2000 123(Pt 5):1027-1040.

16. Doward LC, McKenna SP, Meads DM, Twiss J, Eckert BJ: The development of patient-reported outcome indices for multiple sclerosis (PRIMUS) Multiple Sclerosis 2009, 123(5):1027-1040.

17. Twiss J, Doward LC, McKenna SP, Eckert B: Interpreting scores on multiple sclerosis-specific patient reported outcome measures (the PRIMUS and U-FIS). Health Qual Life Outcomes 2010, 8:117.

18. Sharrack B, Hughes RAC: The Guy's Neurological Disability Scale (GNDS): a new disability measure for multiple sclerosis. Mult Scler 1999, 5(4):223.

19. Horn JL: A Rationale and Test for the Number of Factors in Factor Analysis. Psychometrika 1965, 30:179-185.

20. O'Connor BP: SPSS and SAS programs for determining the number of components using parallel analysis and velicer's MAP test. Behav Res Methods Instrum Comput 2000, 32(3):396-402.

21. Lublin FD: The incomplete nature of multiple sclerosis relapse resolution. J Neurol Sci 2007, 256(Suppl 1):S14-S18.

22. Bartlett $\mathrm{M}$ : A note on the multiplying factors for various $X 2$ approximations. J R Stat Soc B Methodol 1954, 16:296-298.

23. Kaiser HF: An index of factorial simplicity. Psychometrika 1974, 39(1):31-36

24. Kaiser HF: A second generation little jiffy. Psychometrika 1970, 35(4):401-415.

25. Wicks $P$, Vaughan TE, Massagli MP: The multiple sclerosis rating scale, revised (MSRS-R): Development, refinement, and psychometric validation using an online community. Health and Quality of Life Outcomes. Submitted.

doi:10.1186/1477-7525-10-70

Cite this article as: Wicks et al: The multiple sclerosis rating scale, revised (MSRS-R): Development, refinement, and psychometric validation using an online community. Health and Quality of Life Outcomes 2012 10:70.

\section{Submit your next manuscript to BioMed Central and take full advantage of:}

- Convenient online submission

- Thorough peer review

- No space constraints or color figure charges

- Immediate publication on acceptance

- Inclusion in PubMed, CAS, Scopus and Google Scholar

- Research which is freely available for redistribution 